\title{
PLATAFORMAS DIGITAIS E O PROTAGONISMO ESTUDANTIL NO CONTEXTO DO ENSINO REMOTO EMERGENCIAL
}

\author{
Lílian de Sousa Sena ${ }^{1}$ \\ Ilka Márcia R. de Souza Serra²
}

\section{RESUMO}

A utilização de plataformas digitais para a continuidade das aulas no contexto da pandemia da Covid-19 evidenciou o potencial educacional dos ambientes digitais de aprendizagem. A mediação propiciada pelas tecnologias digitais de informação e comunicação - TDICs, além da construção inovadora no processo escolar, propicia experiências interativas que despertam o conhecimento e o respeito às diferenças, principalmente em relação ao repertório linguístico dos falantes maranhenses. O presente artigo tem como objetivo compartilhar a experiência do protagonismo de estudantes do Ensino Médio de uma escola pública da cidade de Timon, no Maranhão, para a realização de um projeto pedagógico de Língua Portuguesa, por meio das plataformas WhatsApp e Jamboard. A ideia foi de apresentar uma vivência pedagógica exitosa com o uso das TDICs, como motivadora para o trabalho colaborativo e construção de saberes. Além da pesquisa bibliográfica, foram realizadas entrevistas com os desenvolvedores do projeto pedagógico. A pesquisa tem abordagem qualitativa e tem como referência, os pressupostos de Moran (2001), Moreira (2018) e Di Felice (2020). Os resultados demonstraram o quanto a apropriação de espaços digitais potencializa a aprendizagem, além de apontar a necessidade de formação de professores para a cultura digital. Ressalta-se ainda a importância de mais pesquisas sobre a atuação dos jovens como gerenciadores de sua aprendizagem em ambientes digitais, de modo que a cibercultura seja uma temática presente e vivenciada nos espaços escolares.

Palavras-chave: Tecnologias Digitais. Protagonismo estudantil. Aprendizagem.

\section{DIGITAL PLATFORMS AND STUDENT PROTAGONISM IN THE CONTEXT OF EMERGENCY REMOTE TEACHING}

\begin{abstract}
The use of digital platforms for students to continue their classes in the context of Covid-19 pandemic showed the educational potential of digital learning environments. The mediation

\footnotetext{
${ }^{1}$ Mestre em Educação Inclusiva pela Universidade Estadual do Maranhão - UEMA. E-mail: liliandisousa@ hotmail.com

${ }^{2}$ Pós-Doutora em Tecnologias Digitais pela Universidade Estadual do Maranhão - UEMA. E-mail: ilka.serra@ uema.br
} 
provided by digital information and communication technologies -DICTs, in addition to the innovative construction in the school process, provides interactive experiences that stimulated knowledge and respect for differences, especially in relation to the linguistic repertoire of Maranhão speakers. This article aims to share the experience of protagonism of high school students in a public school in the city of Timon, Maranhão, to carry out a pedagogical project in Portuguese language, through the WhatsApp and Jambord platforms. The idea was to present a successful pedagogical experience with the use of DICTs, as a motivator for collaborative work and knowledge construction. In addition to bibliographical research, interviews were conducted with the developers of the pedagogical project. The research has a qualitative approach and it's based on the works of Moran (2001), Moreira (2018), and Di Felice (2020). The results showed how the appropriation of digital spaces enhances learning, in addition to pointing out the need for teacher training for digital culture. It is also highlighted the importance of further research on the role of young people as managers of their learning in digital environments, so that cyberculture is a theme present and experienced in school spaces.

Keywords: Digital Technologies. Student Protagonism. Learning.

\section{PLATAFORMAS DIGITALES Y EL PROTAGONISMO ESTUDIANTIL EN EL CONTEXTO DE LA EDUCACIÓN REMOTA DE EMERGENCIA}

\section{RESUMEN}

El uso de plataformas digitales para la continuidad de clases en el contexto de la pandemia Covid-19 destacó el potencial educativo de los ambientes digitales de aprendizaje. La mediación propiciada por las tecnologías digitales de la información y la comunicación TDICs, además de la construcción innovadora en el proceso escolar, propicias experiencias interactivas que despiertan el conocimiento y el respeto a las diferencias, especialmente en lo que respecta al repertorio lingüístico de hablantes de Maranhão. Este artículo tiene como objetivo compartir la experiencia del protagonismo de los estudiantes de la Educación Secundaria, en una escuela pública de la ciudad de Timon, Maranhão, para la realización de un proyecto pedagógico de Lengua Portuguesa a través de las plataformas WhatsApp y Jamboard. La idea era presentar una experiencia pedagógica exitosa con el uso de las TDICs, como motivación para el trabajo colaborativo y la construcción de saberes. Además de la investigación bibliográfica, se realizaron entrevistas con los desarrolladores del proyecto pedagógico. La investigación tiene un enfoque cualitativo y lo estudio se basó en los supuestos de Moran (2001), Moreira (2018) y Di Felice (2020). Los resultados mostraron cómo la apropiación de los espacios digitales favorece el aprendizaje, y pusieron 
de manifiesto la necesidad de formar a los profesores en materia de cultura digital. Esto también pone de manifiesto la importancia de investigar más sobre el papel de los jóvenes como gestores de su aprendizaje en el entorno digital, para que la cibercultura sea un tema presente y vivido en el espacio escolar.

Palabras clave: Tecnologías digitales. Protagonismo estudiantil. Aprendizaje.

\section{INTRODUÇÃO}

A comunicação é uma das principais características do ser humano. É por meio dela que as pessoas se desenvolvem, argumentam, perguntam e instruem. As tecnologias digitais de comunicação e educação - TDICs corroboram para que as interações aconteçam de maneiras mais diversas possíveis e com uma velocidade incomum. Assim, é importante perceber as potencialidades das TDICs para a educação escolar e para o protagonismo estudantil.

Desta feita, a ideia deste trabalho advém da observação do protagonismo de jovens estudantes que, no intuito de continuar com as atividades escolares e um projeto linguístico proposto pela professora de Língua Portuguesa, desenvolveram possibilidades comunicativas e de aprendizagem nos ambientes digitais, no contexto da pandemia da Covid-19.

Durante as aulas de Língua Portuguesa, foram observados diferentes falares entre a comunidade discente do Centro de Ensino Maria Conceição Teófilo Silva, localizado na cidade de Timon, no Maranhão, visto que alguns estudantes trazem uma bagagem linguística diferenciada de suas cidades de origem, o que torna muito enriquecedor o processo de ensino e de aprendizagem.

Partindo do pressuposto de que é um desafio para a maioria dos professores ensinar que se deve utilizar a Língua Portuguesa de acordo com a norma padrão e que se deve também promover a reflexão sobre a existência das variedades linguísticas, conscientizando os jovens de que nenhuma língua é melhor ou pior que a outra. A pesquisa idealizada nesta escola apresentou-se como desafiadora e inovadora no contexto escolar remoto.

Segundo os participantes, a ideia da atividade pedagógica que serve de campo de estudo para este artigo, foi de reunir vocábulos e expressões maranhenses das cidades de Matões, Parnarama e Timon com seus respectivos significados, promovendo, nos alunos, o gosto pela pesquisa, pelo conhecimento da sua cultura e enfatizando o respeito aos diferentes falares maranhenses.

A ideia resultou na estruturação do projeto Expressões Linguísticas do Médio Parnaíba, que foi inscrito e aprovado no edital de n 010/2019 - Geração Ciência da 
Fundação de Amparo à Pesquisa e ao Desenvolvimento Científico e Tecnológico do Maranhão da FAPEMA, que subsidiou a pesquisa com apoio financeiro.

Entretanto, com a pandemia da Covid-19, as aulas presenciais foram suspensas por quase dois anos e o projeto foi interrompido, em sua proposta inicial, que incluía visitas de campo para um contato presencial com entrevistados. Todavia, com as aulas ambientadas em espaços virtuais, muitas aprendizagens foram construídas por professores e alunos, assim, novos entendimentos e estratégias foram criados para que a pesquisa linguística dos jovens continuasse.

Dentre as novas descobertas, surge a ferramenta Jamboard, aliada na materialização da aprendizagem. E é no registro das novas descobertas que o ensino remoto emergencial proporcionou a relevância deste trabalho, pois, em meio à crise sanitária e pouco conhecimento tecnológico por parte do docente, os estudantes deram continuidade à pesquisa e, colaborativamente, reforçaram os laços de amizade, construindo e transmitindo saberes para seus colegas, professores e comunidade física e virtual.

Nesse sentido, perceber que as fronteiras físicas são facilmente ultrapassadas na cibercultura e que diferentes falares e conhecimentos podem se conectar em rede para construir novos saberes são os pontos evidenciados durante esta pesquisa.

Segundo Lemos (2003, p. 11), a cibercultura, "é a cultura contemporânea marcada pelas tecnologias digitais", nela a sociedade está imersa e dela necessita se apropriar. E, sem grandes pretensões, mas com o entusiasmo de quem vê uma luz em meio às trevas, espera-se que outros estudantes e outros professores experienciem o caminhar seguro e criativo em ambientes digitais de aprendizagem.

Portanto, o presente trabalho tem como objetivo analisar a experiência do protagonismo de estudantes do Ensino Médio, para a realização de um projeto pedagógico de Língua Portuguesa, por meio das plataformas WhatsApp e Jamboard, de modo a estimular outras vivências pedagógicas inovadoras com o uso de tecnologias digitais em educação, de maneira colaborativa.

\section{PROCEDIMENTOS METODOLÓGICOS}

Este artigo, de cunho qualitativo, desenvolvido a partir de um estudo de caso sobre um projeto educacional realizado em uma escola pública situada na cidade de Timon, Maranhão, que por forças externas advindas da pandemia da Covid-19 teve seu percurso modificado, proporcionando o contato com as tecnologias digitais e o protagonismo dos estudantes para a concretização de uma atividade pedagógica.

O principal procedimento metodológico utilizado foi a entrevista focalizada com a professora de Língua Portuguesa, idealizadora do projeto. Na entrevista focalizada, segundo Gil (2008, p. 112), "o entrevistador permite ao entrevistado falar livremente sobre 
o assunto, mas quando este se desvia do tema original, esforça-se para sua retomada". Importa esclarecer que a entrevista realizada sob esta perspectiva possibilita ao entrevistado expressar suas vivencias, sem a rigidez de um protocolo a ser seguido, mas sem se afastar dos objetivos iniciais do entrevistador.

Os participantes do projeto em estudo são uma professora de Língua Portuguesa e quatro estudantes do segundo ano do Ensino Médio, todos bolsistas da FAPEMA. Segundo a professora, para a concretização da proposta educacional do componente curricular, os estudantes entrevistaram doze pessoas das cidades de Parnarama, Matões e Timon, no Maranhão. Todo o desenvolvimento, incluindo pesquisa bibliográfica, entrevistas e estruturação do mural virtual teve duração de quinze meses, período compreendido entre março de 2020 e junho de 2021.

O projeto pedagógico realizado na escola propiciou aos envolvidos um novo olhar para os processos interativos e para a construção de conhecimento em ambientes digitais e, como Santana e Moreira (2020) afirmam, na atualidade, é de suma importância conhecer e compreender as múltiplas formas pelas quais professores e alunos se informam e aprendem, de maneira interativa e conectada.

Segundo a entrevistada, as etapas do projeto pedagógico descrito neste artigo foram as seguintes: pesquisas bibliográficas sobre Variedades Linguísticas, história e geografia dos municípios de Parnarama, Matões e Timon entre março e junho de 2020; entrevistas semiestruturadas, entre dezembro de 2020 e fevereiro de 2021, por meio de videochamadas pelo aplicativo WhatsApp, visto que esta é a ferramenta para comunicação mais acessível aos participantes. As entrevistas versavam sobre diferentes assuntos: culinária, música, lendas, clima, esporte, entre outros, a fim de estimular o entrevistado a falar da forma mais natural possível. Entre março e maio de 2021, os alunos pesquisadores fizeram transcrições, anotaram as expressões mais utilizadas e seu respectivo contexto de uso, estruturando o mural virtual na plataforma Jamboard.

A socialização do mural digital, em junho de 2021, foi outra etapa importante do trabalho, pois fortaleceu a valorização das raízes culturais e linguísticas dos maranhenses, ratificando a contribuição das tecnologias digitais para as práticas pedagógicas.

\section{EXPERIÊNCIAS LINGUÍSTICAS}

O ensino da língua materna e toda gama de aquisição da norma padrão e suas variantes implicam também na apropriação de habilidades e competências capazes de proporcionar ao falante da língua o trânsito consciente pela multiplicidade comunicativa. Segundo a Base Nacional Comum Curricular, uma das competências pretendidas com o estudo da linguagem é: 
Compreender as línguas como fenômeno (geo)político, histórico, social, variável, heterogêneo e sensível aos contextos de uso, reconhecendo-as e vivenciando-as como formas de expressões identitárias, pessoais e coletivas, bem como respeitando as variedades linguísticas e agindo no enfrentamento de preconceitos de qualquer natureza. (BRASIL, 2018, p. 493).

A proposta de instigar os jovens a conhecerem as diferentes expressões linguísticas utilizadas em um recorte geográfico, a região conhecida como Médio Parnaíba, do estado do Maranhão, vai ao encontro da proposta que norteia o trabalho com a linguagem, a BNCC. Conhecer e respeitar as diferentes formas de expressão e comunicação é fundamental para as relações interpessoais e convívio no meio social.

$\mathrm{O}$ trabalho com o ensino da língua materna em sala de aula recai sobre o fator de motivar, de forma satisfatória, os alunos, por meio de atividades que venham ampliar seu universo linguístico, bem como despertá-los para o prazer de ler e escrever, permitindo que estes se reconheçam como sujeitos críticos, capazes de refletirem e agirem positivamente, visando o crescimento de seu desempenho como leitor e escritor.

Entretanto, há uma preocupação em se ensinar e aprender a Língua Portuguesa, considerando como válido o normativo culto de sua gramática. Isso gera o preconceito linguístico com aqueles que não a dominam ou não utilizam. Nesse sentido, é necessária uma abordagem que contemple a oralidade e as manifestações culturais na língua de seu povo.

Bagno (2009, p. 18) afirma que:

É preciso, portanto, que a escola e todas as demais instituições voltadas para a educação e a cultura abandonem esse mito da "unidade" do português no Brasil e passem a reconhecer a verdadeira diversidade linguística de nosso país para melhor planejarem suas políticas de ação junto à população amplamente marginalizada dos falantes das variedades não padrão.

Ao trazer esta problematização para a sala de aula, a professora de Língua Portuguesa despertou o interesse pelo falar do outro e promoveu a experiência de se perceber as manifestações vocabulares e socioculturais que compõe não somente o grupo da sala de aula, mas toda a sociedade. E, para o jovem em formação, ter a sensibilidade de enxergar a pluralidade linguística e sua importância cultural, é um contributo para uma comunidade mais empática e respeitosa às diferenças.

Nessa esteira, há que que se considerar também a importância de vivenciar as manifestações linguísticas em ambiente digital e suas implicações para as interações sociais, pois, como pontua Moran (2001, p. 24), "Nunca tivemos tanta informação disponível, tantas tecnologias, mas nunca tivemos também tanta dificuldade de comunicação. Comunicar significa interagir de verdade, todos nós que estamos envolvidos no processo". 
Nessa direção, Sena et al. (2021) consideram que as atividades e estratégias pedagógicas devem ser significativas aos alunos, de modo que suas diferentes realidades estejam presentes nas discussões e possam ser transformadas a partir das interações e do conhecimento construído e a pesquisa linguística, com foco em suas raízes culturais, corrobora para um processo de aprendizagem efetivo.

O envolvimento no processo, em tempos de distanciamento físico, requer também maior engajamento nos momentos interativos. Esse engajamento começa quando o estudante se percebe como parte fundamental no ensino-aprendizagem. Em situações de aulas síncronas, se a postura do professor for a de transmissor de saberes, o aluno que sequer encoraja-se a ligar a câmera, não despertará o entendimento de pertencer e protagonizar vivências de aprendizagem significativa.

Porém, a proposta pedagógica de estudar a própria realidade manifestada pelo falar, fomenta a valorização cultural e a expressão dessa cultura oral, escrita, musicalizada etc. em espaços digitais que eram utilizados somente para entretenimento.

Os estudantes, "precisam ter uma visão crítica, ética e estética, e não somente técnica das TDIC e de seus usos para selecionar, filtrar, compreender e produzir criticamente sentidos em quaisquer campos da vida social". (BRASIL, 2018, p. 497). Assim, o projeto "Expressões linguísticas do Médio Parnaíba" ultrapassa os limites da linguagem e desperta outros saberes.

Segundo Freire (1996, p. 53), "a docência é um trabalho realizado com gente, miúda, jovem ou adulta, mas gente em permanente processo de busca". Assim, propiciar ao aluno buscar e conhecer sua origem, sua cultura, seus falares e suas variantes linguísticas em ambientes digitais ou não, promove a autonomia e a segurança que o estudante precisa para gerenciar seus ritmos e estratégias de aprendizagem, tanto da língua materna como dos outros componentes curriculares.

\section{INTERAÇÕES E APROPRIAÇÕES}

As tecnologias digitais de comunicação trouxeram mudanças significativas nos processos de ensino e aprendizagem, despertando a necessidade de que as comunidades escolares acompanhem a evolução digital para que a formação de seus estudantes contemple também competências digitais.

Competências que se fazem necessárias, pois o digital apresenta inúmeras possibilidades de aprendizagem e formas de relacionamento que impactam em diferentes setores da sociedade. Para Moreira (2018), fundamental é reconhecer a necessidade do processo de ensino ambientado em plataformas digitais que deve ser amparado por estratégias propícias ao desenvolvimento de competências digitais que podem contribuir para o desenvolvimento da aprendizagem. Assim, os projetos educacionais devem também buscar um processo inovador na escola. 
No início do desenvolvimento do projeto pedagógico, os estudantes participantes vivenciaram as tecnologias digitais apenas para entretenimento, desconhecendo ou desconsiderando sua contribuição para a aprendizagem escolar e para a arquitetura de mundo que compõe as redes conectivas. A realidade do ensino remoto emergencial ampliou o olhar dos envolvidos (estudantes e professora) sobre as possibilidades de ensino e de aprendizagem nos ambientes digitais.

Conforme Pessoa e Machado (2019, p. 237), "Trabalhar com a tecnologia computacional em sala de aula é experienciar as diferentes formas de aprendizagem e buscar nelas o próprio conhecimento". Sendo assim, o aluno protagoniza seu processo de aquisição e construção do conhecimento. E, em meio à crise da Covid-19, os estudantes envolvidos no Projeto "Expressões linguísticas maranhenses" revelaram-se verdadeiros atores principais.

No centro de ensino Maria Conceição Teófilo Silva, as aulas no período remoto emergencial, compreendido entre março de 2020 e junho de 2021, utilizaram, em sua maioria, as plataformas WhatsApp, Google Class Room e Jamboard. E, sem conhecimento das possibilidades tecnológicas, a professora de Língua Portuguesa, afirmou que:

\begin{abstract}
"Em meio a tanta incerteza sobre o retorno às aulas presenciais e a preocupação com saúde devido à pandemia, o refúgio foram os estudos. Senti a urgente necessidade de aprender mais para poder interagir com os alunos e diminuir os prejuízos na aprendizagem. Nunca tinha utilizado as ferramentas educacionais Google. Embora tenha participado de algumas formações pela Secretaria de educação, meus alunos foram, para mim, exímios professores" (Professora S).
\end{abstract}

A fala da professora ratifica o que Schlemmer, Di Felice e Serra (2020a) pontua ao mencionar que as tecnologias, na maior parte dos casos, estão sendo usadas como ferramenta, resultando em uma subutilização das possibilidades de aquisição e compartilhamento de saberes no ambiente virtual que podem ser experienciadas no meio físico, transformanto a realidade a partir do conhecimento. Porém, a professora, observando os avanços cognitivos e interativos dos estudantes, percebe o potencial das redes conectivas e as relações nela estabelecidas para o ensino e aprendizagem.

"Compreendi que muito mais que ferramentas, a internet é um mundo em que relações são estabelecidas e, com estas relações, a aprendizagem se constrói e interfere no mundo físico que habitamos. Entendo que esta percepção ainda não pertence a todos na escola, mas aos poucos será comum na comunidade escolar. Assim espero" (Professora S).

O registro da epifania da professora sobre a apropriação das redes conectivas segue a direção de Di Felice (2020), quando assinala que atualmente existem duas pessoas, a material e a digital, e que ambas são verdadeiras, ativas e conectadas. Isto posto, denota- 
se que as interações entre professora e alunos foi essencial para este novo olhar dela sobre as tecnologias.

Esse novo olhar é fundamental, principalmente alinhado ao pensamento de Silva (2001, p. 7) onde:

É preciso enfatizar: o essencial não é a tecnologia, mas um novo estilo de pedagogia sustentado por uma modalidade comunicacional que supõe interatividade, isto é, participação, cooperação, bidirecionalidade e multiplicidade de conexões entre informações e atores envolvidos.

Os estudantes, por sua vez, enveredaram pelas tramas conectivas e deram continuidade à pesquisa de modo virtual, pois entenderam, como Mallagi (2019, p. 77), que "em todos esses espaços, uma grande questão para qualquer ser humano é a busca de uma identidade social que provê um sentido à sua existência". A materialização da atividade pedagógica pode ser observada nas figuras abaixo:

Figura 1 - Página inicial do mural digital

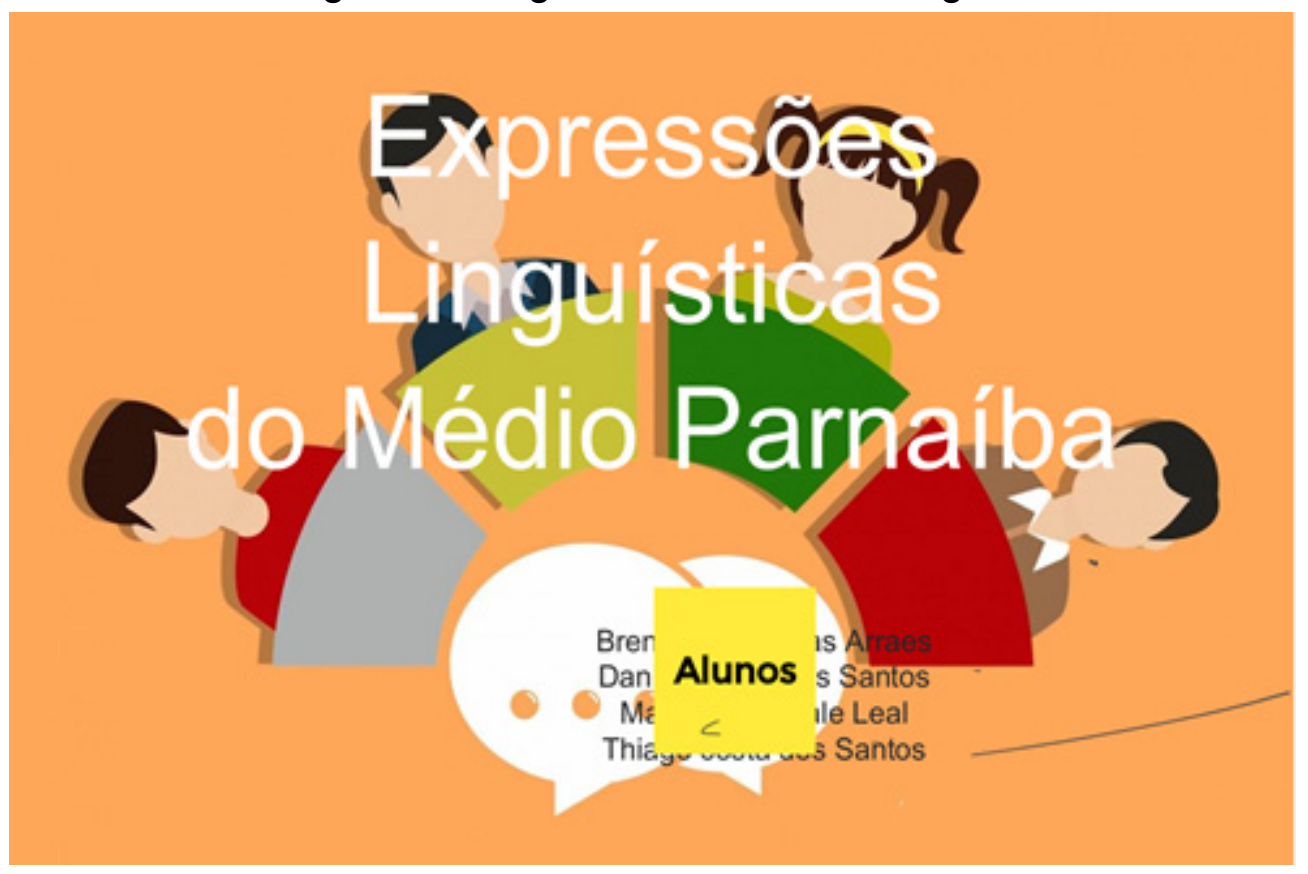

Fonte: Fornecida por participante da pesquisa (2021). 
Figura 2 - Página de apresentação do mural digital

\section{Apresentação}

Os tempos de perdas e de distanciamento físico do ano

letivo de 2020, ensinaram - nos a valorizar cada vez mais

aquilo e aqueles que são nossos. Assim, através da

observação do falar maranhense e da aproximação que

as tecnologias digitais proporcionam, estruturamos os

registros linguisticos comuns na região Médio Parnaiba.

Trabalho feito com dedicação, amizade e aprendizado.

\section{Os autores}

Fonte: Fornecida por participante da pesquisa (2021).

Figura 3 - Amostra do mural digital construído pelos alunos com expressões linguísticas maranhenses.

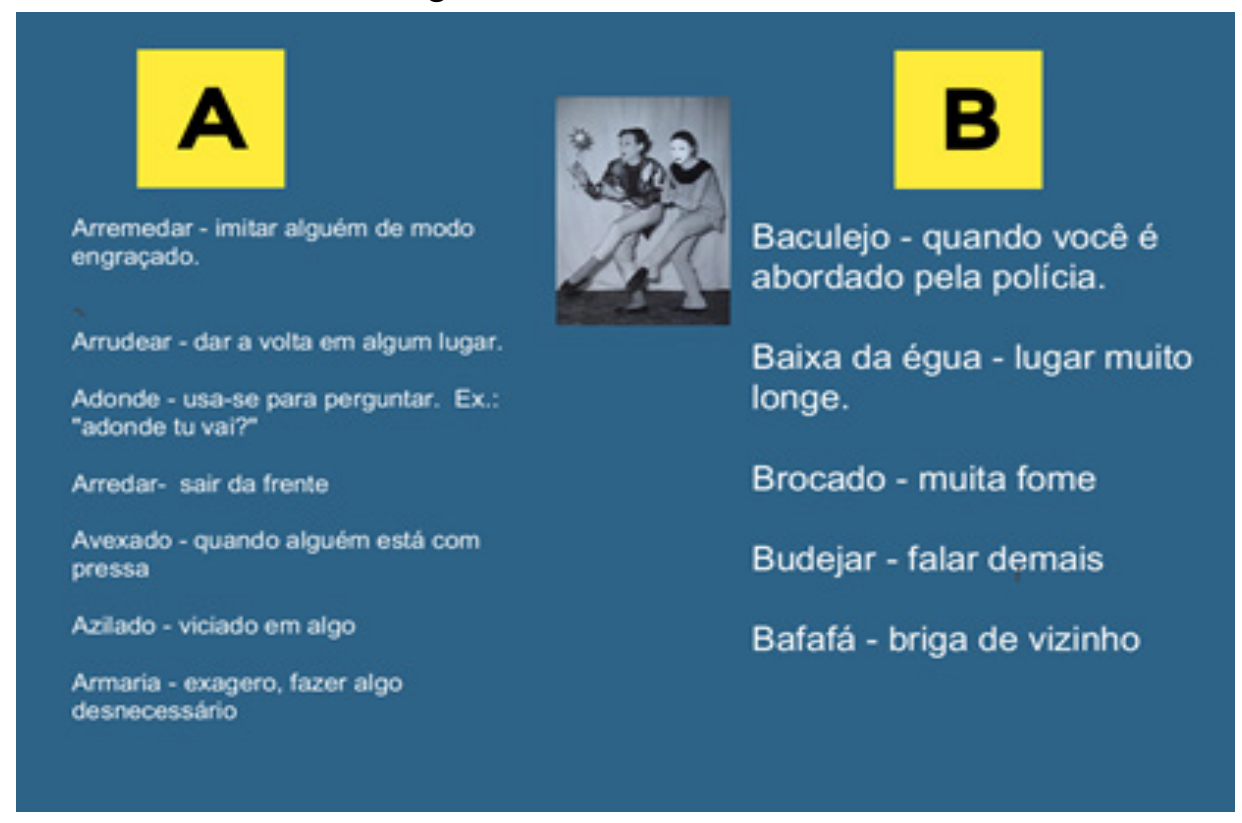

Fonte: Fornecida por participante da pesquisa (2021).

A Jamboard é um recurso muito utilizado para socialização de conhecimento em ambientes digitais. É uma ferramenta gratuita que possibilita a construção coletiva e o engajamento dos participantes. Embora não seja uma novidade para muitos, no centro de ensino onde realizou-se esta pesquisa, o processo foi inovador, pois sua construção 
configurou-se como algo inédito, principalmente pelo distanciamento físico imposto pela necessidade de aulas remotas e pelo empenho dos próprios estudantes.

Os resultados das interações via WhatsApp e Google Class Room materializam o que Moreira (2020, p. 6) afirma quando diz que "a interatividade no digital surge para dar outro significado e ampliar o conceito de interação já existente". Os laços afetivos professora-alunos-escola já eram estabelecidos, a necessidade era continuar o processo de ensino-aprendizagem. Pelo digital, a participação, o trabalho coletivo e o empenho da equipe proporcionaram o protagonismo que se espera em termos de educação escolarizada.

Após a conclusão da pesquisa, os estudantes socializaram em sala virtual ambientada no Google Class Room, para que tanto os colegas de sala quanto os professores das outras disciplinas pudessem reconhecer as expressões linguísticas e marcas da oralidade presentes em seu contexto, de modo a não invalidar tais características de suas manifestações orais da língua. Há ainda que se ressaltar a apropriação das tecnologias digitais de comunicação por parte dos estudantes, ainda que incipiente, para que sua construção de conhecimento continuasse acontecendo.

\section{APRENDIZAGEM COLABORATIVA}

As contribuições dos contextos digitais para a educação são inúmeras. A aprendizagem em rede está para além da inovação. Ela possibilita o desenvolvimento de potencialidades que também são possíveis de se construírem presencialmente, entretanto com uma dimensão mais ampla.

Nesse sentido, importa ressaltar a necessidade de formação continuada para que os professores explorem as possibilidades interativas e de aprendizagem proporcionadas pelos ambientes digitais. Além disso, o estímulo ao trabalho colaborativo, à troca de saberes e o respeito às diferenças devem sempre ser trabalhados no espaço escolar, seja ela físico ou digital.

Na experiência pedagógica observada no Centro de Ensino Maria Conceição Teófilo Silva, a iniciativa dos estudantes em encontrar alternativas viáveis e produtivas para a realização do projeto de Língua Portuguesa, proporcionou à professora da disciplina um novo conhecimento que certamente será utilizado em outras aulas com outros alunos. A postura da professora em querer aprender com seus alunos e estimular o protagonismo estudantil, demonstra que os ambientes digitais, com sua interatividade menos formal, propiciam alternância de papéis que muito somam para o desenvolvimento dos atores envolvidos.

É importante reconhecermos que as aulas ministradas em salas de aula tradicionais, seguem um fluxo bem diferente daquele oferecido nos ambientes digitais. $\mathrm{Na}$ maioria das vezes, as salas físicas apresentam precárias condições estruturais e 
tecnológicas, o que compromete o transitar por outros caminhos que não sejam os da aula tradicional, na qual fica evidente a educação bancária, entendida na perspectiva de Freire (1987, p. 58) como o seguinte processo: "a educação se torna um ato de depositar, em que os educandos são os depositários e o educador o depositante".

Ensinar e aprender em contextos digitais requer mais que conhecimento técnico, necessita de aceitação e abertura aos novos ambientes educacionais. Este aprender e ensinar na era digital não se limita a fronteiras e é exatamente nas não-barreiras que reside a vida do ecossistema digital.

Moreira (2018, p. 14) afirma que:

As tecnologias têm um potencial enorme para melhorar o processo pedagógico, e devem afirmar-se, inseridas em ecossistemas digitais de aprendizagem, como um meio para ajudar o estudante a pensar, a resolver problemas, a criar e a colaborar com os outros.

Nesse sentido, repensar as práticas pedagógicas, buscar informações e ter acesso a formações sobre os novos paradigmas educacionais é necessário. Aprender a pensar colaborativamente e resolver conflitos são ações que competem ao aluno e também ao professor. A aprendizagem é um fluxo constante e as TDICs possibilitam redesenhar os processos de aprendizagem de maneira colaborativa e exitosa.

\section{CONSIDERAÇÕES FINAIS}

Diante das mudanças nos percursos educacionais advindos com a pandemia da Covid-19 e face aos resultados observados nessa experiência pedagógica digital descrita neste estudo, importa destacar a fundamental contribuição das agências de fomento à pesquisa científica, pois em meio aos problemas socioeconômicos enfrentados pelas famílias durante a crise sanitária mundial, o auxílio financeiro subsidiado pela FAPEMA aos participantes contribuiu para que o acesso à internet fosse mantido e o conhecimento continuasse alimentando os sonhos dos estudantes.

Outro aspecto importante observado é a necessidade de políticas públicas visando à inclusão digital, principalmente com relação aos educadores e educandos. A apropriação dos ambientes digitais de aprendizagem é vital para que os professores consigam acompanhar a evolução tecnológica e adquirir competências digitais que o contexto atual, e futuro, espera dos indivíduos. Os alunos, por sua vez, possuem mais conhecimento tecnológico que muitos professores, mas como estão em formação, necessitam de um direcionamento ético para que sua atuação em rede seja construtiva de fato.

Sobre os recursos utilizados, destaca-se o fácil domínio e a gratuidade de algumas ferramentas educacionais, que democratizam o conhecimento e, para o desenvolvimento do 
projeto, contribuíram muito para uma reflexão cultural sobre o falar maranhense e sobre a composição linguística de nossa sociedade. Assim, a partir dessa experiência educacional, espera-se que mais projetos de imersão digital aconteçam em espaços de aprendizagem e que o respeito às diferenças seja sempre a base para as relações presenciais ou virtuais de educação.

\section{REFERÊNCIAS}

BAGNO, Marcos. Preconceito linguístico. 52. ed. São Paulo: Loyola, 2009.

BRASIL. Ministério da Educação. Base Nacional Comum Curricular. Brasília, 2018.

DI FELICE, Massimo. A cidadania digital: a crise da ideia ocidental de democracia e a participação nas redes digitais. São Paulo: Paulus, 2020.

FREIRE, Paulo. Pedagogia da autonomia: saberes necessários à prática educativa. São Paulo: Paz e Terra, 1996.

FREIRE, Paulo. Pedagogia do oprimido. 17. ed. Rio de Janeiro: Paz e Terra, 1987.

GIL, Carlos Antônio. Métodos e técnicas em pesquisa social. São Paulo: Atlas, 2008.

LEMOS, André; CUNHA, Paulo (org.). Olhares sobre a Cibercultura. Porto Alegre: Sulina, 2003. p.11-23.

MALAGGI, Vitor; TEIXEIRA, Adriano Canabarro. Comunicação, tecnologias interativas e educação: (re)pensar o ensinar-aprender na cultura digital.1. ed. Curitiba: Appris, 2019.

MOREIRA, J. António. Reconfigurando Ecossistemas Digitais de Aprendizagens com Tecnologias Audiovisuais Em Rede. Revista de Educação a Distância. São Paulo, v. 5, n.1, p. 5-15, 2018. Disponível em: https://aunirede.org.br/revista_2.4.8-2/index.php/ emrede/article/view/305. Acesso em: 22 set. 2021.

MOREIRA, José António; HORTA, Maria João. Educação e ambientes híbridos de aprendizagem. Um processo de inovação sustentada. Revista UFG, Goiáis, v. 20, n. 26, 2020. Disponível em: https://www.revistas.ufg.br/revistaufg/article/view/66027.

Acesso em: 22 set. 2021.

MORAN, José. Novos desafios na educação: a Internet na educação presencial e virtual. Rio Grande do Sul: UFPel, 2001. p. 19-44. Disponivel em: http://www2.eca.usp.br/ prof/moran/site/textos/tecnologias_eduacacao/novos.pdf. Acesso em: 21 set. 2021.

PESSOA, Regina Ribeiro; MACHADO, Socorro Balieiro. A importância do uso do 
computador no processo de ensino e aprendizagem dos alunos da $3^{a}$ etapa da Educação de Jovens e Adultos da Escola Estadual Joanira Del Castillo. Revista Exitus. Santarém, v. 9, n. 1, p. 232 - 257, jan./mar., 2019. Disponível em: http://www.ufopa.edu.br/ portaldeperiodicos/index.php/revistaexitus/article/view/722. Acesso em: 22 set. 2021.

SANTANA, Camila Lima Santana e; MOREIRA, José António Marques. Cartografando experiências de aprendizagem em plataformas digitais: perspectivas emergentes no contexto das pedagogias das conexões. In: LUCENA, Simone Lucena; NASCIMENTO, Marilene Batista da Cruz; SORTE, Paulo Boa. Espaço de aprendizagem em redes colaborativas e na era da modalidade. Aracaju: EDUNIT, 2020.

SCHLEMMER, Eliane; DI FELICE, Massimo; SERRA, Ilka Márcia Ribeiro de Sousa. Educação OnLIFE: a dimensão ecológica das arquiteturas digitais de aprendizagem. Educar em Revista. Curitiba, v. 36. 2020a. Disponivel em: https://www.scielo.br /j/er/a/5kXJycPzpBZn6L8cXHRMRVy/?format=pdf\&lang=pt. Acesso em: 24 set. 2021.

SENA, Lílian de Sousa; PINHEIRO, Andréa Pestana; SOUSA, Aline de; SERRA, Ilka Márcia R. de Souza. Nuvem de Palavras: estratégia de inclusão e inovação pedagógica. In: SILVA, Rafael Soares. Alinhavos sobre a educação especial na perspectiva inclusiva. Santo Ângelo: Metrics, 2021.

SILVA, Marco. Sala de aula interativa: a educação presencial e a distância em sintonia com a era digital e com a cidadania. In: CONGRESSO BRASILEIRO DA COMUNICAÇÃO, 24., 2001, Resumos [...], . Campo Grande: Sociedade Brasileira de Estudos Interdisciplinares da Comunicação, 2001.

Recebido em 13 de outubro de 2021 Aprovado em 22 de novembro de 2021 